\title{
NOVOS HORIZONTES DA GESTÃO DOS HOSPITAIS UNIVERSITÁRIOS BRASILEIROS: A MUDANÇA DE PARADIGMAS PROMOVIDA PELA EBSERH
}

NEW HORIZONS FOR THE MANAGEMENT OF BRAZILIAN UNIVERSITY HOSPITALS: THE CHANGE OF PARADIGMS PROMOTED BY EBSERH

Ana Flávia Lins SOUTO ${ }^{1}$

Ana Carolina Monteiro Lins de ALBUQUERQUE E SOUTO

Márcio Flávio Lins de ALBUQUERQUE E SOUTO 3

ISSUE DOI: $10.21207 / 1983.4225 .938$

${ }^{1}$ Advogada. Professora Substituta da Universidade Estadual da Paraíba. Graduada em Ciências Jurídicas pelo Centro Universitário de João Pessoa - UNIPÊ. Mestra em Direito pela Universidade Federal do Rio Grande do Norte. Doutora em Ciências Jurídicas e Sociais pela Universidad Del Museo Social Argentino.

${ }^{2}$ Advogada. Professora Substituta da Universidade Federal da Paraíba. Graduada em Ciências Jurídicas e Sociais pela UFPB (2007). Especialista em direito público com ênfase em direito penal Universidade Potiguar (2009). Mestra em Direito Econômico pela Universidade Federal da Paraíba (2017). Doutoranda pela Università Degli Studi di Firenze por meio do convênio com a Universidade Federal da Paraíba.

${ }^{3}$ Advogado. Professor Adjunto II da Universidade Federal da Paraíba. Graduado em Ciências Jurídicas pelo Centro Universitário de João Pessoa - UNIPÊ (2005). Especialista em direito processual "lato sensu" pela Unama (2008). Mestre em Direito Econômico pela Universidade Federal da Paraíba (2009). Doutor em Ciências Jurídicas e Sociais pela Universidad Del Museo Social Argentino (2013). Doutorando pela Università Degli Studi di Firenze por meio do convênio com a Universidade Federal da Paraíba. 


\title{
RESUMO
}

A administração pública brasileira estava diminuindo a carga de eficiência em relação aos demais países do mundo, em razão da histórica imutabilidade de sua organização institucionalizada e burocrática. No início do século XXI, observou-se um processo de reformulação da administração pública que implicou na ruptura de paradigmas historicamente concebidos e que se mostravam anacrônicos em comparação com aquele apresentado por outras nações. Esta mudança é claramente verificada em relação à gestão pública dos hospitais universitários que migraram - em muitos Estados da Federação - das universidades federais para a Empresa Brasileira de Serviços Hospitalares - a EBSERH - cuja criação foi autorizada pela lei federal n. ${ }^{\circ} 12.550$ de 15 de dezembro de 2011 e nasceu imbuída da finalidade de aumentar a carga de eficiência dos serviços públicos de saúde no Brasil. Esta empresa pública representa um novo modelo de prestação de serviços de saúde em comparação com aquele oferecido ao longo de todo o século XX pelo Poder Público e encontra resistência em muitas universidades em relação à sua implantação, mas se apresenta como um caminho viável para a reestruturação de todo o funcionalismo público brasileiro.

Palavras-chave: Saúde. Serviços Públicos. EBSERH.

\begin{abstract}
The Brazilian public administration was decreasing the efficiency load in relation to the other countries of the world, due to the historical immutability of its institutionalized and bureaucratic organization. At the beginning of the 21 st century, there was a process of reformulation of public administration that implied the rupture of historically conceived paradigms that were anachronistic in comparison with that presented by other nations. This change is clearly seen in relation to the public management of university hospitals that have migrated - in many States of the Federation - from federal universities to the Brazilian Hospital Services Company - EBSERH - whose creation was authorized by federal law No. 12,550 of 15 December 2011 and was born imbued with the purpose of increasing the efficiency load of public health services in Brazil. This public company represents a new model for the provision of health services in comparison to that offered throughout the 20th century by the Government and finds resistance in many universities in relation to its implementation, but it presents itself as a viable path for restructuring. of all Brazilian civil servants.
\end{abstract}

Keywords: Health. Public Services. EBSERH.

\section{INTRODUÇÃO}

O presente texto dissertativo tem por escopo analisar a administração pública brasileira engendrada ao longo do século passado, bem como as modificações observadas na primeira década do atual, com especial ênfase para a gestão dos hospitais universitários após o advento da lei federal n. ${ }^{\text {o }} 12.550$ de 15 de dezembro de $2011^{4}$, que criou a Empresa Brasileira de Serviços Hospitalares - EBSERH.

É importante destacar a metodologia que será utilizada para o desenvolvimento deste trabalho que, não obstante possa ser classificado como eminentemente doutrinário, tem um forte caráter empírico-

\footnotetext{
${ }^{4}$ BRASIL. Lei Federal n ${ }^{\circ} 12.550$ de 15 de dezembro de 2011.
} 
pragmático no sentido de que busca tecer comentários sobre o serviço público de saúde que será oferecido no Brasil ao longo do século XXI.

Sinteticamente, pode-se enumerar três tipos de pesquisas jurídicas: a epistemológica, a sócio jurídica e a instrumental. A primeira é a mais abstrata, observa o ordenamento jurídico como um terceiro expectador sob o ponto de vista valorativo; a segunda estuda o direito de fora para dentro, assim como a anterior, mas sem adotar a postura estática, isto é, avalia o pensamento da sociedade em relação ao direito de maneira pragmática, e a terceira parte do sentido oposto, tentando dotar o ordenamento jurídico de mecanismos hábeis para efetivar direitos. Esta última é desenvolvida de três formas: doutrinária, correspondente a maior parcela das pesquisas e é representada pela obra dos estudiosos; legislativa, que engloba a produção dos legisladores e a jurisprudencial, que observa o comportamento dos tribunais.

Por outro lado, há quatro métodos de procedimento utilizados normalmente: o histórico, que parte da pesquisa temporal para situar o objeto do estudo presente, correlacionando-o com modelos anteriores; comparativa, que se assemelha com a anterior, mas avalia outros ordenamentos jurídicos contemporâneos; interpretativo, que prima pela imparcialidade subjetiva do pesquisador e o crítico, caracterizado pelo personalismo individualista de quem escreve.

A rigor, os trabalhos científicos empregam mais de um tipo de pesquisa e um método de procedimento, embora sempre se possa destacar um de cada de maneira nuclear. Pode-se dividir o presente estudo em relação aos objetivos geral e específicos.

Para o desenvolvimento deste estudo, é possível vislumbrar o objetivo geral de discutir novos modelos de administração pública a serem desenvolvidos ao longo do século XXI, e, neste sentido, é fácil perceber que a pesquisa pautar-se-á pelo tipo instrumental, pois abordará argumentos dialéticos que compatibilizem o a gestão da saúde nas formas: doutrinária e legislativa, pelo método de procedimento interpretativo; em relação ao objetivo específico, especialmente voltado para a criação da EBSERH, observar-se-á a pesquisa sócio jurídica pelos métodos de procedimento histórico e comparativo, procurando desde o modelo político-administrativo empregado no século XX até os novos horizontes que se apresentam à administração pública como um todo. Todavia, nada impede que os outros tipos de pesquisa e métodos de procedimento sejam 
utilizados para enriquecer o presente estudo, tendo em vista a variabilidade dos temas tratados.

\section{DA ADMINISTRAÇÃO PÚBLICA INDIRETA}

A administração pública brasileira está organizada por meio de vários critérios de fragmentação, que vão desde a divisão políticoadministrativa nacional, compreendendo os entes federativos típicos: União, Estados, Distrito Federal e Municípios, até a divisão por unidades autônomas de atuação, tais como as empresas públicas e sociedades de economia mista.

A administração pública direta refere-se à atuação do próprio ente político para o atendimento das necessidades sociais. Por exemplo, quando o Poder Público pretende construir uma dada rodovia, pode fazêlo diretamente distribuindo servidores para atuarem na obra - o que não acontece na prática - ou contratando, em respeito ao devido processo legal instituído, após a devida licitação, uma empresa que ficará responsável pela entrega da obra nos termos do contrato administrativo. Todos os entes políticos atuam diretamente para o atendimento das necessidades públicas, isto é, União, Estados, Distrito Federal e Municípios são as pessoas jurídicas de direito público interno que atuam na administração pública direta. Nenhum outro ente goza de personalidade jurídica própria para personificar a chamada administração pública direta. Entretanto, deve-se chamar a atenção, para o fato de que cada ente pode possuir subdivisões orgânicas que não se confundem com a administração pública indireta nem são suscetíveis de atribuição de uma personalidade jurídica própria. Nesse sentido, é possível visualizar que um dado Estado da Federação possui várias secretarias e, cada uma delas, embora represente uma unidade administrativa interna, com suas matérias típicas, não detém personalidade jurídica própria, v. g., as secretarias de saúde, de educação, de segurança pública e etc.

Considerando a impossibilidade prática da administração pública atuar diretamente em todas as obras e serviços públicos desenvolvidos, surgiu a chamada administração pública indireta, que decorre da ideia de descentralização, onde os vários entes políticos criam entidades autônomas com atribuições fixadas em lei, competentes para prestar serviços ou realizar obras públicas de interesse social. Dessa forma, é possível 
visualizar na organização da administração pública brasileira dois núcleos de atuação principais: a administração direta desempenhada pelos entes políticos e a administração pública indireta desenvolvida por meio de entes criados por iniciativa dos entes políticos. Ou seja, enquanto a administração pública direta é exercida diretamente por meio da União, dos Estados, do Distrito Federal e dos Municípios, estes, por sua vez, podem criar outros entes para atuarem nas áreas mais relevantes para o interesse social.

São entes da administração pública indireta contemporânea: as autarquias, fundações, empresas públicas e as sociedades de economia mistas. No curso do século XX, surgiram as agências executivas e as agências reguladoras, que, na verdade, não são novas figuras da administração pública indireta, mas especializações que derivaram das próprias autarquias e que ganharam relevo considerando o novo perfil do Estado Regulador. Em regra, as empresas públicas e sociedades de economia mistas estão voltadas para a exploração da atividade econômica, mas vale destacar que, mesmo entre estas figuras a jurisprudência reconhece pessoas jurídicas com maior carga de prestação de serviços públicos do que de exploração da atividade econômica, tais como, a Empresa Brasileira de Correios e Telégrafos e a Infraero. Por outro lado, autarquias e fundações públicas estão prioritariamente comprometidas com a prestação de serviços públicos, mesmo que recorrentemente logrem a exploração da atividade econômica, não se podendo falar de uma divisão hermética das áreas de atuação de cada um destas entidades.

\section{AS UNIVERSIDADES FEDERAIS E OS HOSPITAIS UNIVERSITÁRIOS BRASILEIROS NO SÉCULO XX}

A educação pública brasileira é um tema exaustivamente tratado no bojo da constituição federal, ou seja, o legislador constituinte dedicou especial atenção à promoção e difusão do conhecimento científico no país. A rigor, não há uma exclusividade sobre qual ente político poderá criar universidades públicas, isto é, todas as pessoas jurídicas de direito público interno podem criar suas universidades a depender dos seus atos normativos, posto que a $\mathrm{CF} / 88^{5}$ quando tratou da educação, atribuiu competência comum:

\footnotetext{
${ }^{5}$ BRASIL, Constituição da República Federativa do. Promulgada em 05 de outubro de 1988.
} 
Art. 23. É competência comum da União, dos Estados, do Distrito Federal e dos Municípios: [...] V - proporcionar os meios de acesso à cultura, à educação, à ciência, à tecnologia, à pesquisa e à inovação;

Art. 24. Compete à União, aos Estados e ao Distrito Federal legislar concorrentemente sobre: [...] IX - educação, cultura, ensino, desporto, ciência, tecnologia, pesquisa, desenvolvimento e inovação;

Portanto, todos os entes federativos podem criar suas universidades para proporcionar o ensino público superior. Não obstante haja esta liberdade a favor dos entes federativos, a própria $\mathrm{CF} / 88^{6}$ discriminou áreas de preferência, onde cada pessoa jurídica de direito público deveria atuar:

Art. 211. A União, os Estados, o Distrito Federal e os Municípios organizarão em regime de colaboração seus sistemas de ensino. [...] $\S 2^{\circ}$ Os Municípios atuarão prioritariamente no ensino fundamental e na educação infantil.

$\S 3^{\circ}$ Os Estados e o Distrito Federal atuarão prioritariamente no ensino fundamental e médio.

Dessa forma, o legislador constituinte discriminou áreas de atuação preferencial em matéria de educação para cada um dos entes federativos, tendo-se valido da expressão "prioritariamente" para sempre deixar em aberto a possibilidade de interpenetração de cada um dos entes nas demais etapas do ensino. Como foi visto, os Municípios devem atuar prioritariamente nos ensinos fundamental e infantil, os Estados e Distrito Federal no ensino fundamental e médio, deixando por meio do critério residual a atribuição preferencial da União sobre o ensino público superior. Não obstante haja este comando constitucional, os Estados podem criar suas próprias universidades e isto se verifica em várias unidades da federação. A rigor, não há qualquer óbice como foi visto, mas, vale destacar que as demais áreas de atuação restam vulneradas quando um ente invade a competência prioritária de outro. Isso é bem observado no caso das universidades estaduais. Como em regra, elas atraem os profissionais com maior titulação acadêmica, sempre se corre o risco de que o fisiologismo de seus funcionários postule ao poder público os maiores salários, em detrimento dos professores do ensino médio e fundamental que, na verdade, vinculam-se preferencialmente aos Estados. Neste sentido, em um

\footnotetext{
${ }^{6}$ BRASIL, Constituição da República Federativa do. Promulgada em 05 de outubro de 1988.
} 
cenário ideal, seria importante que cada unidade da federação obedecesse ao comando constitucional, dando maior relevo a cada uma das áreas estabelecidas.

As universidades públicas federais brasileiras sempre se destacaram no contexto deste país como a referência nacional em todos os aspectos do ensino superior, compreendendo as atividades de ensino, pesquisa e extensão, bem como, no caso dos cursos de ciências médicas, pela administração dos hospitais universitários.

Antes do advento das universidades públicas federais, havia as várias faculdades superiores espalhadas e sem uma unidade de organização administrativa comum. No século $\mathrm{XX}$, foram criadas as universidades públicas em todos os Estados da Federação com o escopo de promover e difundir o ensino superior em todos os cantos do país.

Neste sentido, a Universidade Federal da Paraíba foi criada por meio da federalização de outras faculdades que já existiam no âmbito deste Estado, v. g., Faculdade de Direito, Faculdade de Medicina e Faculdade de Filosofia, bem como pela criação de todos os outros cursos superiores que hoje integram a UFPB. Em relação às Ciências da Saúde, que englobam vários cursos superiores, tais como, enfermagem, farmácia, fisioterapia e etc., além do próprio curso de medicina, faziam-se necessária a existência de um hospital-escola que servisse de iniciação prática para todos estes estudantes. Dessa forma, em $1980^{7}$, foi inaugurado o hospital universitário Lauro Wanderley, que atende às necessidades pedagógicas de formação dos estudantes dos cursos de saúde da UFPB, bem como, presta serviços públicos de saúde para a população em geral, recebendo pacientes de todos os Municípios do Estado.

\section{O NOVO PARADIGMA DE PRESTAÇÃO DE SERVIÇOS HOSPITALARES NO BRASIL}

O serviço público no Brasil tem sido marcado, no início deste século XXI, por um processo de reconfiguração que rompeu com os paradigmas históricos e determinou o desenvolvimento de novos modelos de administração, mais voltados para a obtenção de resultados.

\footnotetext{
${ }^{7}$ BRASIL. História da instalação do Hospital Universitário Lauro Wanderley em João Pessoa - PB. Disponível no endereço eletrônico http://www.ebserh.gov.br/web/hulw-ufpb/nossa-historia. Acesso em 10 de setembro de 2015.
} 
Neste sentido, foi marcante a criação da Empresa Brasileira de Serviços Hospitalares - EBSERH -, por meio da lei federal ${ }^{8}$ n. ${ }^{\circ} 12.550$ de 2011, que tem como objetivos principais':

a) Aumentar a carga de eficiência nos serviços públicos de saúde oferecidos pelos hospitais universitários;

b) Separar a gestão pública dos hospitais universitários da administração autárquica das universidades;

c) Introduzir servidores ligados ao funcionalismo público por meio de vínculos celetistas paralelamente aos servidores estatutários;

d) Assegurar o controle sobre a continuidade dos serviços públicos de saúde que têm uma demanda crescente e contínua, razão pela qual devem ser desenvolvidos de maneira ininterrupta;

e) Permitir que os hospitais universitários aufiram receitas próprias por meio da exploração da atividade econômica, embora tenha como finalidade principal a prestação de serviços públicos nos termos dos art. $3 .^{\circ}$ e $8 .^{\circ}$ respectivamente da lei da EBSERH ${ }^{10}$.

Como foi dito alhures, a organização político-administrativa brasileira pressupõe a divisão em direta e indireta, sendo aquela desenvolvida por meio dos entes políticos, e esta, por meio de pessoas jurídicas criadas a partir dos anteriores. Vale destacar que, em relação aos serviços públicos de saúde, há hospitais públicos criados institucionalmente com a finalidade de prestar serviços de saúde, v. g., hospital Clementino Fraga e Napoleão Laureano, que possuem natureza jurídica de fundações públicas de direito público, e os hospitais públicos universitários que se inserem dentro da organização administrativa das universidades, isto é, já derivam das funções de uma autarquia preexistente.

Após a criação da EBSERH, várias instituições públicas de saúde migraram para sua gestão administrativa, ou seja, empregando uma noção atécnica, foram incorporadas à sua estrutura, vindo a compor seu patrimônio social. O mesmo aconteceu com vários dos hospitais universitários que existiam no corpo das universidades públicas federais, por meio de um processo de integralização que encontrou muita resistência entre os membros da comunidade acadêmica. Esta migração dos HU's da estrutura das universidades federais para a EBSERH contou com uma resistência renhida, especialmente, por parte dos servidores que compõem os HU's e que são vinculados por meio do regime jurídico estatutário. Nesse sentido, vale destacar que nem todos os HU's foram incorporados

\footnotetext{
8 . Op. Cit., nota 01.

${ }^{9}$ Estes objetivos principais não estão expressos na lei de criação da EBSERH, mas são facilmente verificáveis a partir da própria leitura do art. $3^{\circ}$ da lei de criação.

${ }^{10}$ BRASIL. Op. Cit., nota 01.
} 
pela EBSERH, v. g., o hospital universitário da UFCG, enquanto outros foram transferidos desde o início da EBSERH, como, por exemplo, o Hospital Universitário Lauro Wanderley que se encontrava vinculado à Universidade Federal da Paraíba.

No Brasil, um servidor público pode vincular-se ao quadro do funcionalismo basicamente por meio de dois liames funcionais: o estatutário ou o celetista. Aquele foi o vínculo mais difundido ao longo do século XX e que conta com a maior carga de prerrogativas funcionais, tais como, estabilidade, aposentadoria por meio de um regime próprio, direitos sociais, todos previstos no estatuto jurídico dos servidores públicos civis a lei n. ${ }^{\circ} 8.112 / 90^{11}$, enquanto estes são ligados ao serviço público por meio de regime de direito privado, como um típico contrato de trabalho desenvolvido na relação jurídico-obrigacional que tem como empregador a EBSERH e como empregado a pessoa física. Não obstante, os servidores celetistas sejam selecionados por meio de concurso público, assim como os estatutários, eles não gozam das mesmas prerrogativas estabelecidas na lei n. ${ }^{\circ} 8.112 / 90$, posto que seus contratos podem ser extintos nos termos da $\mathrm{CLT}^{12}$.

A diversidade de vínculos entre os servidores que compõem os HU's após a implantação da EBSERH é talvez a maior crítica que se faz a esta nova formatação na gestão da saúde brasileira. Enquanto o regime estatutário mostrava-se como o único adotado, seus servidores logicamente gozavam de uma maior carga de força política nos pleitos do funcionalismo, ao passo que a convivência simbiótica de servidores vinculados a dois regimes enfraquece a ambos, pois, se os celetistas postulam mais direitos por meio de movimentos paredistas, os estatutários continuam a prestação dos serviços, e vice-versa.

Algumas das características inovadoras da EBSERH também merecem bastante cautela por parte dos administradores das unidades de saúde. Nesse sentido, pode-se destacar: "Art. 5ํ É dispensada a licitação para a contratação da EBSERH pela administração pública para realizar atividades relacionadas ao seu objeto social ${ }^{13}$." Ora, a contratação com o Poder Público por meio de licitação é uma das maiores garantias constitucionais, pois assegura a impessoalidade, a isonomia, a eficiência e se manifesta como uma das maiores marcas do Estado Democrático, mas, Lei Federal no 8.112 de 1990. Estatuto dos Servidores Públicos Civis. Consolidação das Leis do Trabalho. Decreto-lei n. ${ }^{\circ} 5.452$ de $1 .^{\circ}$ de maio de 1943. Op. Cit., nota 01. 
ainda assim, a lei apenas faculta a esta empresa pública a realização do certame licitatório. A própria lei de licitações e contratos ${ }^{14}-$ lei federal $n$. $^{\circ}$ 8.666/93 - já contempla diversas hipóteses em que não se mostra necessária a licitação, todavia, a lei de regência criou mais um privilégio genérico para a EBSERH quando dispensou amplamente o processo licitatório. Não obstante se possa enfatizar a relevância dos serviços de saúde como sendo aptos a justificar a não obrigatoriedade de licitação, deve-se lembrar que as hipóteses concretas da lei de licitação e contratos já serviria para compatibilizar a celeridade na realização dos contratos com a probidade administrativa que deve sempre ser garantida.

\section{$5 \quad$ CONCLUSÕES}

Como visto, o Brasil passa por um processo de reestruturação de sua organização político-administrativa que encontra reflexo especial na gestão da saúde pública até então prestada à população.

A EBSERH apresenta-se como um novo modelo de gestão que rompeu com o paradigma desenvolvido ao longo do século passado. Este fenômeno pode encontrar precedentes históricos no processo de diminuição da máquina administrativa empreendido na década de 90 , se não sob o ponto de vista da privatização, quando o Poder Público delegou para a iniciativa privada do desempenho de funções anteriormente exercidas com monopólio, mas, pelo menos na finalidade de otimização dos serviços públicos que se mostravam engessados à luz de um modelo que atentava contra a eficiência do serviço público. Portanto, a mera disposição política dirigida por este desiderato merece que se encare como uma notícia alvissareira a ruptura com a gestão da saúde pública anterior à EBSERH.

Como resultados concretos da criação da EBSERH, podem ser apontados:

a) A criação de uma gestão mais voltada para os resultados na prestação de serviços públicos de saúde;

b) A desvinculação dos HU's das estruturas das universidades para serem inseridas na organização da EBSERH;

c) A cumulação de regimes jurídicos diversos na vinculação dos servidores com os hospitais da EBSERH e, 
d) Um maior controle por parte dos administradores públicos sobre a continuidade dos serviços prestados.

Além dos serviços públicos de saúde, há uma tendência verificável em outros setores de uma reestruturação do funcionalismo também em outras áreas, mas a preocupação com este setor e a necessidade de aumentar a eficiência do mesmo, fizeram com que o governo desse o pontapé inicial deste processo que pode espalhar-se pelas demais áreas de atuação.

\section{REFERÊNCIAS BIBLIOGRÁFICAS}

BRASIL, Constituição da República Federativa do. Promulgada em 05 de outubro de 1988.

BRASIL. Lei Federal nº 12.550 de 15 de dezembro de 2011.

BRASIL. História da instalação do Hospital Universitário Lauro Wanderley em João Pessoa - PB. Disponível no endereço eletrônico http://www.ebserh.gov.br/web/hulw-ufpb/nossa-historia . Acesso em 10 de setembro de 2015.

. Lei Federal nº 8.112 de 1990. Estatuto dos Servidores Públicos Civis.

Consolidação das Leis do Trabalho. Decreto-lei n. ${ }^{\circ} 5.452$ de $1 .^{\circ}$ de maio de 1943. 